\title{
Evaluation of the treatment of II and III degree hemorrhoids: A comparison of mucosa suspension procedure for prolapse and hemorrhoids, Shenyang city, China, 2006-2009
}

\author{
Duo Song, MD ${ }^{1}$, Xian-wei Dal, MD², Chun-sheng Chen, MD²
}

\section{SUMMARY}

Objective: The aim of this study was to evaluate the effect of mucosa suspension procedure (MSP) by comparing procedure for prolapse and hemorrhoids (PPH).

Methods: We compared the safety, clinical outcome, and cost between PPH and MSP for the surgical treatment of hemorrhoidal disease. A total of 80 patients with II and III degree hemorrhoids were included in the study. MSP group ( $n=40$ ) and PPH group $(\mathrm{n}=40)$ were applied at random.

Results: Both MSP and PPH are safe surgical treatments for patients with II and III degree hemorrhoids. Complications of the patients, such as persistent pain and tenesmus in the MSP group were less than the PPH group. Moreover, MSP had lower costs.

Conclusion: MSP is a safe, effective, and inexpensive procedure for patients with hemorrhoidal disease. We consider that this technique should be widely used.

Keywords: Hemorrhoids; Mucosa; Suspension; Prolapse.

Colomb Med. 2011; 42: 219-23

Comparación de técnicas quirúrgicas para el tratamiento de las hemorroides grado II-III, Shenyang, China, 2006-2009

\section{RESUMEN}

Objetivo: El objetivo del estudio fue comparar la seguridad, los resultados clínicos y el costo entre el procedimiento quirúrgico de suspensión de la mucosa y el manejo quirúrgico del prolapso para el tratamiento de las hemorroides.

Métodos: Se incluyeron en el estudio 80 pacientes quienes presentaban hemorroides sintomáticas grado II y III; 40 (50\%) recibieron como tratamiento el procedimiento quirúrgico de suspensión de la mucosa y 40 (50\%) recibieron el manejo quirúrgico del prolapso.

Resultados: Ambos tratamientos quirúrgicos fueron eficientes y seguros observando una menor proporción de persistencia del dolor y tenesmo con el procedimiento quirúrgico de suspensión de la mucosa con costos más bajos para este tipo de cirugía.

Conclusión: La suspensión de la mucosa es un procedimiento eficaz, seguro y de bajo costo para los pacientes con enfermedad hemorroidal. Esta técnica debería usarse más ampliamente.

Palabras clave: Hemorroides; Mucosa; Suspensión; Prolapso.

Colomb Med. 2011; 42: 219-23

Hemorrhoidal disease is very common among infrared ray photocoagulation, electro-coagulation, patients $^{1,2}$. There are many kinds of treatments, including sclerotherapy and closed or open hemorrhoidectomy ${ }^{3}$.

1. Assistant Professor, Department of Colon and Rectal Surgery, Shengjing Hospital of China Medical University, Shenyang, China. e-mail: sdhappy2009@hotmail.com

2. Full Professor, Department of Colon and Rectal Surgery, Shengjing Hospital of China Medical University, Shenyang, China. e-mail: cmu2cmu2@126.comzzglnsysj@hotmail.com

Received for publication April 29, 2010 Accepted for publication October 19, 2010 
Table 1

Patient demographics and disease severity for mucosa suspension procedure (MSP) and prolapse and hemorrhoids (PPH)

\begin{tabular}{lcc}
\hline \multirow{2}{*}{ Characteristics } & \multicolumn{2}{c}{ Treatment group } \\
\cline { 2 - 3 } & MSP $(\mathbf{n = 4 0 )}$ & PPH $(\mathbf{n = 4 0 )}$ \\
\hline Men & 15 & 19 \\
Women & 25 & 21 \\
Mean age (range) & $48(22-78)$ & $52(23-76)$ \\
II degree & 18 & 16 \\
III degree & 22 & 24 \\
\hline
\end{tabular}

Although each has its specific indications, the procedure for prolapse and hemorrhoids (PPH) is currently considered one of the most effective treatment methods ${ }^{4,5}$. Since the first description of PPH by Longo in $1998^{4}$, this procedure has been widely accepted and used in the common clinical practice in curing II and III degree hemorrhoids ${ }^{5}$. Nonetheless, the safety of this method has been recently questioned after reports of persistent postoperative pain and fecal urgency following the proce-dure ${ }^{5-7}$. Furthermore, the high cost of disposable stapler becomes an unpopular option for patients ${ }^{8}$.

With this background, we set up the technique and described that mucosa suspension procedure (MSP) reduced hemorrhoidal prolapse. This is possible by reducing and fixing a transverse band of prolapsed rectal mucosa between the rectal ampulla and the anal canal.

The technique can protect the anal mucosa and also avoid the risk of complications like persistent postoperative pain and fecal urgency. Furthermore, the cost of surgery was greatly reduced with this technique. The aim of this study was to present our experience in patients with II and III degree hemorrhoids treated with MSP.

\section{MATERIALS AND METHODS}

Subjects. From June 2006 to February 2009, a total of 80 patients with II and III degree hemorrhoids were included in the study (46 women). They were randomized into two groups according to a list generated by using a random number of tables: 1) mucosa suspension procedure (MSP) (40 patients) and 2)

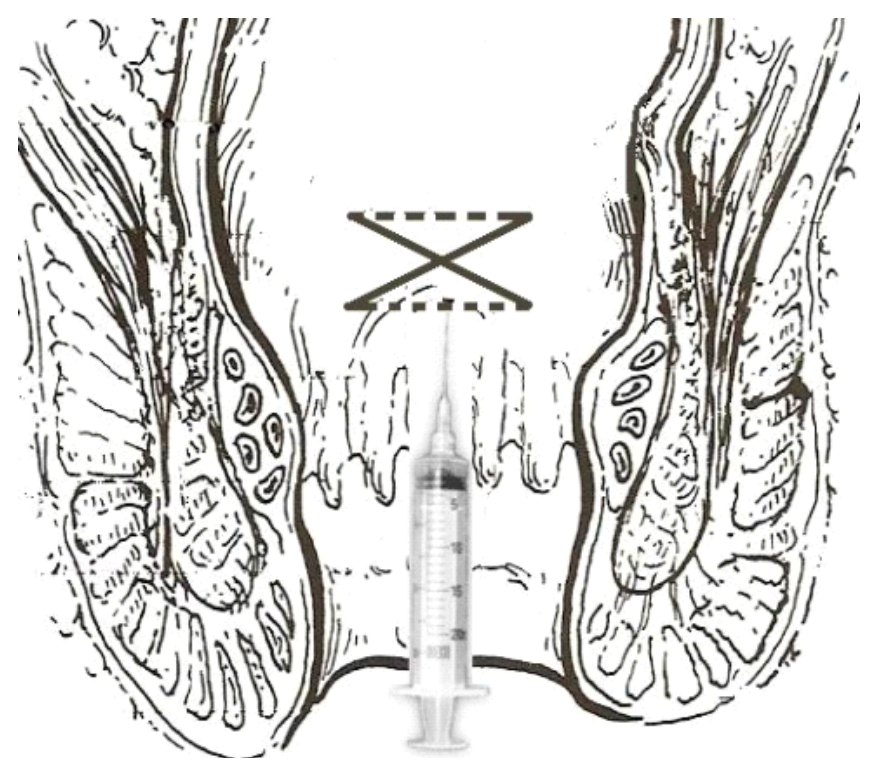

Figure 1. Mucosa suspension procedure

procedure for prolapse and hemorrhoids (PPH) (40 patients). Preoperative evaluation of continence and hemorrhoidal disease was performed. Patient demographics and disease severity for both groups are shown in Table 1. This clinical trial was approved by the ethics committee of our institution, and informed consent was obtained from each patient. Clinical history of chronic, and autoimmune, such as coagulopathies, was considered a criterion of exclusion. Postoperatively, the patients were seen for follow-up after one week and again after one, 6 weeks and 6 months.

Statistical analysis. These analyses were performed with SPSS 13.0 for Windows (SPSS, Chicago, Ill., USA). Probability values of less than 0.05 were considered statistically significant.

Surgical technique. After subdural anesthesia, the patients in the MSP group were placed in lithotomy position. The dentate line is easily identified and $4 \mathrm{~cm}$ proximally to it. Z-shaped suture at four points in 3,6, 9, 12 o'clock were prepared in the rectal mucosa and submucosa with 2-0 Prolene sutures. The distance between two sutures is $0.5-1.0 \mathrm{~cm}$. Submucosa in the previous four sites were injected with $4 \mathrm{ml}$ of $5 \%$ phenol in arachis oil into each site, which could fix loose rectal mucosa (Figure 1). Those in the PPH group were performed according to technical guidelines described in literature for PPH as described by Longo ${ }^{4}$.

Case costing. We performed a cost analysis to determine whether there was a significant difference in 
hospital costs between the methods. We obtained a cost per unit of operating room time, and the value was estimated at US $\$ 5.00$ per minute. Moreover, the cost of a one-day hospital stay in a cure surgical unit was estimated at US\$200. We obtained the exact cost of the stapler in hospital. It included the cost of all disposables.

\section{RESULTS}

In the MSP group, the mean operative time was 27 minutes and there were no intraoperative complications. All patients had the procedure performed as inpatients. The average stay for the entire group was 1.5 days (range 1-3 d). Three patients ( $8 \%$ ) had postoperative complications, including significant bleeding (1), pain (1), and urinary retention (1) (Table 2). At 6-week follow-up, 36 patients $(90 \%)$ were satisfied and had no complaints about the surgery and its results. Four patients were not completely satisfied. The complaints included mild fecal incontinence (2), bleeding (1), and recurrence (1).

Forty patients underwent PPH. Mean operative time was 25 minutes. There were no intraoperative complications. All patients had the procedure performed as inpatients. The average length of hospitalization for the entire group was 1.3 days (range 1-3 d) (Table 3). A total of 4 patients $(10 \%)$ had postoperative complications, including severe pain (1), urinary retention (2), and significant bleeding (1)(Table 2). At 6-week followup, 32 patients $(80 \%)$ were satisfied and had no complaints about the surgery and its results. Eight patients were not completely satisfied. Four patients complained of fecal urgency and tenesmus. Two patients complained of tenesmus and bleeding. Four patients complained of persistent pain. Two patients complained of persistent pain and incontinence. The average total cost of MSP was calculated at US $\$ 435.00$, while the total cost of PPH was US\$1010.71 (Table 3).

\section{DISCUSSION}

This study showed that MSP involved less persistent pain, tenesmus and lower cost in II and III degree hemorrhoids than PPH. Since the first description of PPH by Longo in $1998^{4}$, this technique has been widely adopted to treat II and III degree hemorrhoids as an alternative to traditional surgery ${ }^{5}$. But the stapled
Table 2

Postoperative complications and follow-up complaints for mucosa suspension procedure (MSP) and prolapse and hemorrhoids (PPH)*

Complications and MSP $(n=40) \quad P P H(n=40)$
complaints

\begin{tabular}{lll}
$\begin{array}{l}\text { Postoperative } \\
\text { complications }\end{array}$ & \\
\hline Pain & 1 & 1 \\
\hline Bleeding & 1 & 1 \\
\hline Urinary retention & 1 & 2 \\
\hline Complaints at follow-up & & \\
\hline Recurrence & 1 & 0 \\
\hline Pain & 0 & 6 \\
\hline Bleeding & 1 & 2 \\
\hline Tenesmus and/or urgency & 0 & 6 \\
\hline Incontinence & 2 & 2 \\
\hline
\end{tabular}

${ }^{*} p<0.05$

Table 3

Operative time, length of hospital stay and hospital cost comparison for mucosa suspension procedure (MSP) and prolapse and hemorrhoids (PPH)*

Characteristics $\quad$ MSP $(n=40)$ PPH $(n=40)$

\begin{tabular}{|c|c|c|}
\hline Average operative time, $\min$ & 27 & 25 \\
\hline Mean length of stay (d) & 1.5 & 1.30 \\
\hline \multicolumn{3}{|l|}{ Operative costs (US\$) } \\
\hline Cost of stapler & 0.0 & 625.71 \\
\hline Cost of operating room time & 135.0 & 125.00 \\
\hline \multicolumn{3}{|l|}{ Postoperative costs } \\
\hline Cost of stay & 300.0 & 260.00 \\
\hline Total cost & 435.0 & 1010.71 \\
\hline
\end{tabular}

${ }^{*} p<0.05$

hemorrhoidectomy is not offered for fourth degree disease because of the difficulty in visualizing the anal canal and introducing the stapler ${ }^{9-12}$.

Analyzing the results of the two procedures, the recurrence rate after MSP is one patient and no evidence of statistically significant difference with relapses after 
PPH. Both MSP and PPH are safe surgical treatments for patients with II and III degree hemorrhoids (Table 2 ). Both groups were given the same analgesic regimen on the day of surgery. These differences in short-term postoperative pain did not reach statistical significance between the two techniques. The main point of discussion is the persistent pain after $\mathrm{PPH}$, which is reported for a period lasting up to 6-12 months and ranging from 2 to 31 percent $^{5-7}$. It is confirmed by the long-term results in our series, in which the symptom is present in $15 \%$ of patients with $\mathrm{PPH}$, but in none of those who underwent MSP. The incidence of bleeding in long-term follow-up is 5\% in patients with $\mathrm{PPH}$ and only one in patients with MSP. No significant differences between the two tehniques. The incidences of shortterm urinary retention were similar in both groups. One patient with MSP with this complication was treated with in-and-out catheterization in the surgical evening. Two patients with PPH with this complication required intermittent catheterization for 1 and 2 days. The defecation disturbances after $\mathrm{PPH}$, like tenesmus or urgency, are reported with a greater degree of incidence ${ }^{5,6,13-15}$. Ortiz et al. ${ }^{13}$ showed that this symptom was present in $40 \%$ of the patients with $\mathrm{PPH}$ at one-year follow-up. In our series, tenesmus is present in $15 \%$ of the patients with PPH and in none of patients with MSP, and the difference is statistically significant. Functional results after MSP and PPH are similar in our series. There were no statistically significant differences between the two methods in connection with major incontinence, dirt, and gas control.

The average operative time was almost identical in both techniques. We also found the total calculated institution costs for both procedures to be significantly different (Table 3). In our opinion, the cost of the disposable (PPH kit) in the stapler group is higher than the cost in the MSP group. The length of stay for procedure is almost same for both groups. The cost and the average total length of hospital stay calculated in our study are within the range of published results from similar studies in the literature. Ho YH et al. ${ }^{8}$, found the stapled hemorrhoidectomy to be more expensive than conventional therapy in their series. The systematic follow-up of each patient at 6 weeks postoperatively showed that satisfaction with the results of surgery was substantially higher in MSP group. Specifically, there were fewer complaints of persistent pain.

\section{CONCLUSION}

This study showed that the complications of the patients, such as persistent pain and tenesmus, in the MSP group were less than in the PPH group. MSP had a lower cost in II and III degree hemorrhoids than PPH. Our results suggest that MSP is a safe, effective, and inexpensive procedure for patients with hemorrhoidal disease. We consider that this technique should be used widely.

Conflict of interest. None of the authors has conflicts of interest related to this study.

\section{REFERENCES}

1. Chong PS, Bartolo DC. Hemorrhoids and fissure in ano. Gastroenterol Clin North Am. 2008; 37: 627-44.

2. Sneider EB, Maykel JA. Diagnosis and management of symptomatic hemorrhoids. Surg Clin North Am. 2010; 90:1732.

3. Correa-Rovelo JM, Téllez O, Obregón L, Miranda-Gómez A, Moran S. Stapled rectal mucosectomy vs. closed hemorrhoidectomy a randomized, clinical trial. Dis Colon Rectum. 2002; 45: $1367-75$.

4. Longo A. Treatment of haemorrhoid disease by reduction of mucosa and haemorrhoidal prolapse with a circularstapling device: a new procedure. In Proceedings of the 6thWorld Congress of Endoscopic Surgery, 1998. p. 777-84.

5. Cheetham MJ, Mortensen NJ, Nystrom PO, Kamm MA, Phillips RK. Persistent pain and faecal urgency after stapled haemorrhoidectomy. Lancet. 2000; 356: 730-3.

6. Cheetham MJ, Cohen CR, Kamm MA, Phillips RK. A randomized, controlled trial of diathermy hemorrhoidectomy $v s$. stapled hemorrhoidectomy in an intended day-care setting with longer-term follow-up. Dis Colon Rectum. 2003; 46: 491-7.

7. Oughriss M, Yver R, Faucheron JL. Complications of stapled hemorrhoidectomy: a French multicentric study. Gastroenterol Clin Biol. 2005; 29: 429-33.

8. Ho YH, Cheong WK, Tsang C, Ho J, Eu KW, Tang CL, et al. Stapled hemorrhoidectomy: cost and effectiveness. Randomized controlled trial including incontinence scoring, anorectal manometry, and endoanal ultrasound assessments at up three months. Dis Colon Rectum. 2000; 43: 1666-75.

9. Khalil KH, O'Bichere A, Sellu D. Randomized clinical trial of sutured versus stapled closed haemorrhoidectomy. Br J Surg. 2000; 87: 1352-5.

10. Rowsell M, Bello M, Hemingway DM. Circumferential mucosectomy (stapled haemorrhoidectomy) versus conventional haemorrhoidectomy randomized controlled trial. Lancet. 2000; 355: 779-81.

11. Hetzer FH, Demartrines N, Handschin AE, Clavien PA. Stapled vs. excision hemorrhoidectomy. Long-term results of a prospective randomized trial. Arch Surg. 2002; 137: 337-40. 
12. Wilson MS, Pope V, Doran HE, Fearn SJ, Brough WA. Objective comparison of stapled anopexy and open hemorrhoidectomy: a randomized, controlled trial. Dis Colon Rectum. 2002; 45: 1437-44.

13. Ortiz H, Marzo J, Armendáriz P, Miguel MD. Stapled hemorrhoidopexy vs. diathermy excision for fourth degree hemorrhoids: a randomized, clinical trial and review of the literature. Dis Colon Rectum. 2005; 48: 809-15.
14. Touzin E, Hegge S, McKinley C. Early experience of stapled hemorrhoidectomy in a community hospital setting. Can J Surg. 2006; 49: 316-20.

15. Smith EF, Baker RP, Wilken BJ, Hartley JE, White TJ, Monson JR. Stapled versus excision haemorroidectomy: longterm follow-up of a randomised controlled trial. Lancet. 2003; 361: $1437-8$. 